Original Research Paper

\title{
Analysis of the Interaction between the Lining of a TBM Tunnel and the Ground Using the Convergence-Confinement Method
}

\author{
Pierpaolo Oreste \\ Department of Environmental, Land and Infrastructural Engineering, \\ Politecnico di Torino (Italy), Corso Duca degli Abruzzi 24, I-10129 Torino Italy
}

\author{
Article history \\ Received: 15-04-2015 \\ Revised: $27-05-2015$ \\ Accepted: 02-06-2015 \\ E-mail: pierpaolo.oreste@polito.it
}

\begin{abstract}
The support used when a tunnel is excavated by a shielded TBM is complex because it consists of two different materials: A concrete segmental lining and a filler annulus between the lining and the tunnel wall. A detailed analysis of the behavior of such a support system requires a three-dimensional numerical modeling and should also consider the presence of the TBM machine. This article presents an analytical calculation procedure that allows to assess the interaction between the support system and the tunnel using the convergence-confinement method and Vlachopoulos-Diederichs method. Furthermore, it is defined the overall stiffness of the support system starting from the detailed analysis of the stresses and strains developed in the two constituent materials. From the analysis of the evolution of the radial displacements in the longitudinal section, it was then possible to evaluate another fundamental parameter: The radial displacement of the tunnel wall at the point of installation of the support system. The computational procedure was then applied to a specific case, showing the influence of the stiffness of the filling material on the final loads acting on the segmental lining.
\end{abstract}

Keywords: Tunnel Stability, Deep Tunnel, Circular Tunnel, ConvergenceConfinement Curve, Tunnel Support, Stress and Strain Around the Tunnel, TBM, Shielded TBM, Segmental Lining, Filling Material, Reaction Line, Support Stiffness

\section{Introduction}

Often nowadays tunnels are excavated through the use of machines TBMs (Benato and Oreste, 2015). The construction of a tunnel with shielded TBM machines requires the realization of a concrete lining (segmental lining) in the tail of the machine, at a certain distance from the excavation face (10-12 m). Such a lining is put into operation within the shield and the hollow space between the tunnel wall and the lining extrados is generally filled with gravel material, sometimes cemented. The support system is, therefore, represented by a less rigid outer ring (ring composed by natural or cemented gravel) and an inner ring of concrete (the segmental lining) (Fig. 1).

The assessment of the overall stiffness of the support system is very important because this stiffness influences the loads acting on the support itself: The higher the stiffness, the greater the loads which act on the lining.
Furthermore, it appears to be very important to know the radial displacement $u_{R, \text { in }}$ of the tunnel wall in the moment in which the lining is inserted. This radial displacement also has effect on the final applied loads.

A thorough analysis of the interaction between a tunnel excavated by shielded TBM and segmental lining can be developed with the numerical modeling, preferably of three-dimensional type (Do et al., 2014a; 2014b). This modeling turns out to be quite complex and computation times are typically high.

For this reason, in this study an analytical procedure for the assessment of the interaction between the lining and the tunnel, when a shielded TBM machine is used, is presented. The analytical methods are widespread in tunnelling and help solve problems of great importance in relation to the stability around the tunnel and on the excavation face and to the design of the support and reinforcement structures (Oreste, 2009; 2013; Osgoui and Oreste, 2007). The procedure is based 
on the convergence-confinement method and uses the results of the studies developed by (Vlachopoulos and Diederichs, 2009) for the evaluation of the longitudinal profile of the radial displacements of the tunnel wall.

The convergence-confinement method is an analytical calculation method widespread in the tunneling field (Ribacchi and Riccioni, 1977; Panet, 1995; AFTES, 1993). It allows to study the behavior of a tunnel in a simple and intuitive way, obtaining the evaluation of the relationship between the applied internal pressure and the radial displacement of the wall. The method appears to be fast and analyzes the interaction between the tunnel and the support through the intersection of the characteristic curve of the tunnel with the reaction line of the support. Precisely for the speed of calculation and for the accuracy of the results, this method was also used in the past for studies of probabilistic (Oreste, 2005) and back-analysis type.

The reaction line of the support is, therefore, essential to be able to analyze the behavior of a segmental lining in tunnels excavated by a shielded TBM. For this reason will be evaluated in the following the stiffness of the composite support system consisting of the segmental lining and of an outer ring of filler material. Furthermore, in order to position with some precision the reaction line with respect to the characteristic curve of the tunnel, it is necessary to understand the evolution of the radial displacements of the wall in the longitudinal section. The theoretical profile of (Vlachopoulos and Diederichs, 2009) will be modified to take into account the presence of the TBM shield.

Through the developed procedure will be possible to arrive at estimating the load acting on the segmental lining and, therefore, define the value of its thickness and the steel reinforcement necessary to ensure the stability of the tunnel.

\section{Materials and Methods}

The convergence-confinement method expects to obtain the intersection between the characteristic curve of the tunnel (convergence-confinement curve) and the reaction line of the support (Fig. 1).

The slope of the reaction line with respect to the horizontal is a function of the stiffness of the support system sostegno $\mathrm{k}_{\mathrm{sys}}\left(\operatorname{tg} \vartheta=\mathrm{k}_{\mathrm{sys}}\right)$. In order to properly evaluate the stiffness of the composite system consisting of the segmental lining and the outer ring of filler material, it is necessary to analyze in detail the stresses and strains developed in the two materials, when the tunnel wall has radial displacements subsequent to the lining installation $\left(\mathrm{u}_{\mathrm{R}}-\mathrm{u}_{\mathrm{R}, \text { in }}\right)$ (Fig. 2).

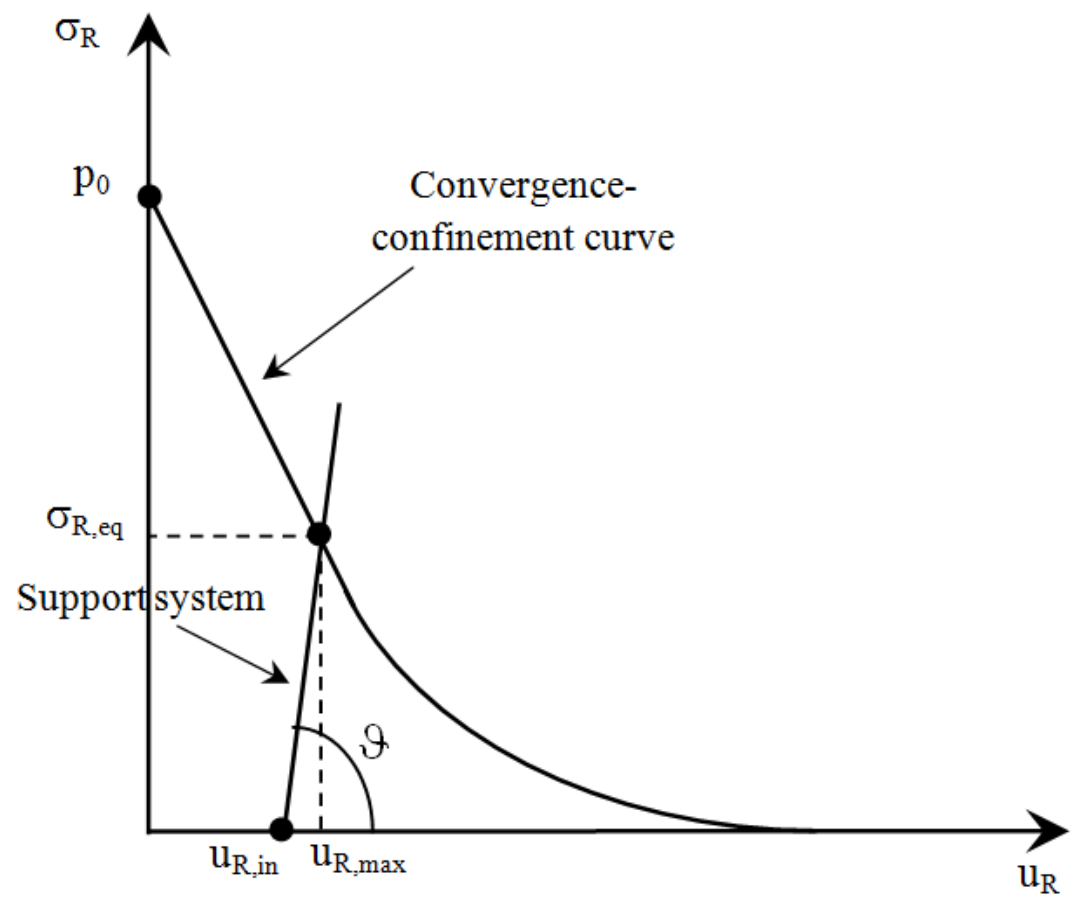

Fig. 1. The characteristic curve of the tunnel (convergence-confinement curve) and the reaction line of the support. The intersection point is used to determine the final load acting on the support $\left(\sigma_{\mathrm{R}, \mathrm{eq}}\right)$ and the final displacement of the tunnel wall $\left(\mathrm{u}_{\mathrm{R}, \max }\right)$. Key: $\mathrm{u}_{\mathrm{R}, \text { in }}$ : Displacement of the tunnel wall at the time of installing the support; $\sigma_{\mathrm{R}}$ : Radial pressure applied on the tunnel wall; $\mathrm{u}_{\mathrm{R}}$ : Radial displacement of the tunenl wall; $\mathrm{p}_{0}$ : Lithostaticstress to the depth of the tunnel; $\vartheta$ : Slope of the reaction line of the support with respect to the horizontal $\left(\operatorname{tg} \vartheta=\mathrm{k}_{\text {sys }}\right.$, with $\mathrm{k}_{\text {sys }}$ the stiffness of the support system) 


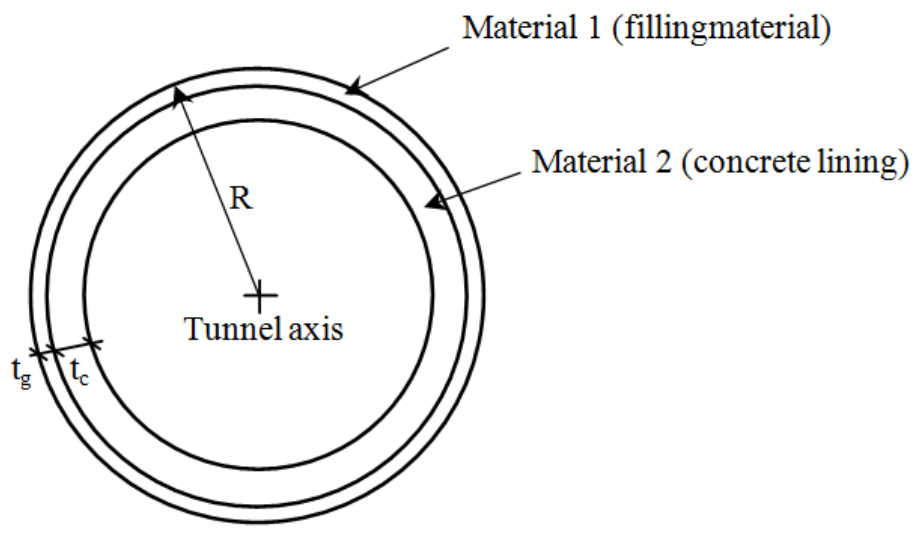

Fig. 2. Composite support system when the tunnel is excavated by a shielded TBM. The outer ring is formed by the filling material (material 1), the inner ring is the segmental lining (material 2). The extrados of the outer ring coincides with the tunnel wall, having a radius $\mathrm{R} ; \mathrm{t}_{\mathrm{g}}$ : Thickness of the outer ring; $\mathrm{t}_{\mathrm{c}}$ : Thickness of the inner ring

For the radial symmetry, the radial displacement $u$ in the two rings is expressed by the following general formulation, in function of the generic distance from the center of the tunnel $r$ (Ribacchi and Riccioni, 1977):

$$
u=A \cdot r+\frac{B}{r}
$$

Because the shear deformation $\varepsilon_{\vartheta}$ is the ratio $\mathrm{u} / \mathrm{r}$ and the radial deformation $\varepsilon_{\mathrm{r}}$ is the derivative of $u$ with respect to $\mathrm{r}\left(\varepsilon_{\mathrm{r}}=\mathrm{du} / \mathrm{dr}\right)$, we have:

$$
\begin{aligned}
& \varepsilon_{\vartheta}=A+\frac{B}{r^{2}} \\
& \varepsilon_{r}=A-\frac{B}{r^{2}}
\end{aligned}
$$

Furthermore, for the radial symmetry in a field of plan deformations, one can write the following relations between stresses and strains:

$$
\begin{aligned}
& \sigma_{\vartheta}=C \cdot \varepsilon_{\vartheta}+D \cdot \varepsilon_{r} \\
& \sigma_{r}=C \cdot \varepsilon_{r}+D \cdot \varepsilon_{\vartheta}
\end{aligned}
$$

Where:

$$
C=\frac{1-v}{(1-2 \cdot v) \cdot(1+v)} \cdot E \quad D=\frac{v}{(1-2 \cdot v) \cdot(1+v)} \cdot E
$$

$\mathrm{E}=$ The elastic modulus of the material;

$v=$ The Poisson ratio of the material.

The following boundary conditions of the support system are posed:
- Radial displacement on the extrados of the outer ring (material 1) equal to: $\left(u_{R}-\mathrm{u}_{\mathrm{R}, \text { in }}\right)$ for $\mathrm{r}=\mathrm{R}$, where $\mathrm{u}_{\mathrm{R}, \text { in }}$ is the displacement of the tunnel wall at the time when the lining is installed and $u_{R}$ is the generic displacement of tunnel wall

- Radial stress $\sigma_{\mathrm{r}}$ at the interface between the two materials $\left(\mathrm{r}=\mathrm{R}-\mathrm{t}_{\mathrm{g}}\right)$, equal for the two materials

- Radial displacement $\mathrm{u}$ at the interface between the two materials $\left(\mathrm{r}=\mathrm{R}-\mathrm{t}_{\mathrm{g}}\right.$ ), equal for the two materials

- Nil radial stress $\sigma_{\mathrm{r}}$ at the intrados of the second material: $\sigma_{\mathrm{r}}=0$ for $\mathrm{r}=\left(\mathrm{R}-\mathrm{t}_{\mathrm{g}}-\mathrm{t}_{\mathrm{c}}\right)$

For condition 1 one can write the following relation (from Equation 1):

$u=\left(u_{R}-u_{R, i n}\right)=A_{1} \cdot R+\frac{B_{1}}{R}$

From which:

$B_{1}=R \cdot\left[\left(u_{R}-u_{R, i n}\right)-A_{1} \cdot R\right]$

For the second condition one can write the following relation (from Equation 2-5):

$$
\begin{aligned}
& C_{1} \cdot\left[A_{1}-\frac{B_{1}}{\left(R-t_{g}\right)^{2}}\right]+D_{1} \cdot\left[A_{1}+\frac{B_{1}}{\left(R-t_{g}\right)^{2}}\right] \\
& =C_{2} \cdot\left[A_{2}-\frac{B_{2}}{\left(R-t_{g}\right)^{2}}\right]+D_{2} \cdot\left[A_{2}+\frac{B_{2}}{\left(R-t_{g}\right)^{2}}\right]
\end{aligned}
$$

where, $A_{1}$ and $B_{1}, A_{2}$ and $B_{2}: A$ and $B$ parameters, respectively for material landmaterial 2; $C_{1}$ and $D_{1}, C_{2}$ and $\mathrm{D}_{2}: \mathrm{C}$ and $\mathrm{D}$ parameters, respectively for material 1 and material $2 ; t_{\mathrm{g}}$ is the thickness of external annulus (the gravel stratum, material 1); this thickness is 
typically equal to the thickness of the shield in the tail zone $t_{\text {sh }}$, but may be higher when there is a significant over break by the TBM head (this aspect will be discussed in more detail below).

For condition 3 one can write the following relation (from Equation 1):

$$
A_{1} \cdot\left(R-t_{g}\right)+\frac{B_{1}}{\left(R-t_{g}\right)}=A_{2} \cdot\left(R-t_{g}\right)+\frac{B_{2}}{\left(R-t_{g}\right)}
$$

From which, substituting Equation 8 to $\mathrm{B}_{1}$ :

$$
B_{2}=A_{1} \cdot\left[\left(R-t_{g}\right)^{2}-R^{2}\right]-A_{2} \cdot\left(R-t_{g}\right)^{2}+\left(u_{R}-u_{R, i n}\right) \cdot R
$$

For Condition 4 one can write the following relation (from Equation 2-5):

$$
C_{2} \cdot\left[A_{2}-\frac{B_{2}}{\left(R-t_{g}-t_{c}\right)^{2}}\right]+D_{2} \cdot\left[A_{2}+\frac{B_{2}}{\left(R-t_{g}-t_{c}\right)^{2}}\right]=0
$$

where, $t_{c}$ is the thickness of the inner annulus (concrete lining, material 2).

Substituting Equation11 in Equation 12, after a few steps we get:

$$
A_{1}=\xi \cdot A_{2}+\rho \cdot\left(u_{R}-u_{R, i n}\right)
$$

Where:

$$
\begin{aligned}
& \xi=\frac{\alpha \cdot\left(D_{2}-C_{2}\right)-D_{2}-C_{2}}{\left(D_{2}-C_{2}\right) \cdot(\alpha-\beta)} \rho=\frac{C_{2}-D_{2}}{\left(D_{2}-C_{2}\right) \cdot(\alpha-\beta)} \cdot \frac{\beta}{R} \\
& \alpha=\frac{\left(R-t_{g}\right)^{2}}{\left(R-t_{g}-t_{c}\right)^{2}} \beta=\frac{R^{2}}{\left(R-t_{g}-t_{c}\right)^{2}}
\end{aligned}
$$

Replacing Equation 8 and 11 in Equation 9, after some steps we get:

$$
\omega \cdot A_{1}=2 \cdot C_{2} \cdot A_{2}+\chi \cdot\left(u_{R}-u_{R, i n}\right)
$$

Where:

$$
\begin{aligned}
& \omega=C_{1} \cdot(1+\eta)+D_{1} \cdot(1-\eta)+C_{2} \cdot(1-\eta)-D_{2} \cdot(1-\eta) \\
& \chi=\left(D_{2}-C_{2}+C_{1}-D_{1}\right) \cdot \frac{\eta}{R} \quad \eta=\frac{R^{2}}{\left(R-t_{g}\right)^{2}}
\end{aligned}
$$

Solving the system composed of the Equation 13 and 14 in the two unknowns $A_{1}$ and $A_{2}$, we get:

$$
\begin{aligned}
& A_{1}=\left(\xi \cdot \frac{\chi-\omega \cdot \rho}{\omega \cdot \xi-2 \cdot C_{2}}+\rho\right) \cdot\left(u_{R}-u_{R, i n}\right) \\
& A_{2}=\left(\frac{\chi-\omega \cdot \rho}{\omega \cdot \xi-2 \cdot C_{2}}\right) \cdot\left(u_{R}-u_{R, i n}\right)
\end{aligned}
$$

The stiffness of the support system $\mathrm{K}_{\text {sys }}$ is given by the ratio between the radial stress $\sigma_{R}$ on the tunnel wall ( $\mathrm{r}$ $=\mathrm{R})$ and the displacement at that point:

$$
\begin{aligned}
& k_{s y s}=\frac{\sigma_{R}}{\left(u_{R}-u_{R, \text { in }}\right)}=\frac{C_{1} \cdot\left(A_{1}-\frac{B_{1}}{R^{2}}\right)+D_{1} \cdot\left(A_{1}+\frac{B_{1}}{R^{2}}\right)}{\left(u_{R}-u_{R, \text { in }}\right)} \\
& =\frac{\left(C_{1}+D_{1}\right) \cdot A_{1}+\frac{\left(D_{1}-C_{1}\right)}{R^{2}} \cdot B_{1}}{\left(u_{R}-u_{R, \text { in }}\right)}
\end{aligned}
$$

From which, by replacing the Equation 15 and 8 in Equation 17, after a few steps we get:

$$
k_{s y s}=2 \cdot C_{1} \cdot\left(\xi \cdot \frac{\chi-\omega \cdot \rho}{\omega \cdot \xi-2 \cdot C_{2}}+\rho\right)+\frac{1}{R} \cdot\left(D_{1}-C_{1}\right)
$$

The other fundamental parameter in order to draw the reaction line of the support of Fig. 1 is the radial displacement of the tunnel wall at the moment in which the support is installed $\left(\mathrm{u}_{\mathrm{R}, \text { in }}\right)$ (Oreste, 2009; 2013). According to Vlachopoulos and Diederichs (2009) radial displacements $u_{R}$ have the following evolution (curve 1 in Fig. 3):

$u_{R}=u_{R, \max } \cdot\left[\left(\frac{1}{3} \cdot e^{-0.15 \cdot \frac{R_{p l}\left(\sigma_{R, e q}\right)}{R}}\right) \cdot e^{\frac{x}{R}}\right]$

for negative $\times$ (ahead of the excavation face)

$u_{R}=u_{R, \max } \cdot\left[1-\left(1-\frac{1}{3} \cdot e^{-0.15 \cdot \frac{R_{p l}\left(\sigma_{R, e q}\right)}{R}}\right) \cdot e^{-\frac{3 \cdot x}{2 \cdot R_{p l}\left(\sigma_{R, e q}\right)}}\right]$

for positive $\times$ (behind the excavation face)

where, $\mathrm{R}_{\mathrm{pl}}\left(\sigma_{\mathrm{R}, \mathrm{eq}}\right)$ : Plastic radius of the tunnel in the presence of an internal pressure equal to the final pressure $\left(\sigma_{R, e q}\right)$ applied by the support structure to the tunnel wall.

In the absence of over break, the presence of a shielded TBM involves blocking of the radial displacements immediately behind the TBM head, in correspondence of the excavation face. For the whole length $\mathrm{L}$ of the TBM shield radial displacements of the tunnel wall are stationary equal to the $\mathrm{u}_{\mathrm{R} \text {,in }}$ value which is present in correspondence of the excavation face (curve 2 of Fig. 3): 
$u_{R, i n}=u_{R, \max } \cdot\left(\frac{1}{3} \cdot e^{-0.15 \cdot \frac{R_{p l}\left(\sigma_{R, e q}\right)}{R}}\right)$

It can be assumed that for $\mathrm{x}>\mathrm{L}$ the trend of $\mathrm{u}_{\mathrm{R}}$ remains the same as the curve 1 , shifted by $L$ along the $\mathrm{x}$ axis.

In practice, the effect of the shielded TBM is to freeze the radial displacements along the whole of the TBM shield (from $\mathrm{x}=0$ to $\mathrm{x}=\mathrm{L}$ ) and to transfer the position of the face at the installation point of the lining.

$\delta$ in Fig. 3 represents the prevented displacement by the presence of the TBM shield:

$$
\delta=u_{R, \max } \cdot\left[\left(1-\frac{1}{3} \cdot e^{-0.15 \cdot \frac{R_{p l}\left(\sigma_{R, e q}\right)}{R}}\right) \cdot\left(1-e^{-\frac{3 \cdot x}{2 \cdot R_{p l}\left(\sigma_{R, e q}\right)}}\right)\right]
$$

To this displacement corresponds a radial pressure $p$ acting on the extrados of the shield: This pressure can be evaluated by applying the displacement $\delta$ to the characteristic curve of the tunnel (Fig. 4). Since both $\delta$ and $\mathrm{p}$ vary along the shield (Fig. 3 ), the value of $\mathrm{p}$ along $\mathrm{x}$ (from $\mathrm{x}=0$ to $\mathrm{x}=\mathrm{L}$ ) can be integrated in order to evaluate the total frictional force on the interface shield-tunnel wall that it is necessary to win during the TBM advancement.

Instead, if the TBM head realizes an over break $\Delta$, i.e., the tunnel radius $\mathrm{R}$ is greater than the shield radius $R_{s h}\left(\Delta=R-R_{s h}\right)$, the profile of the radial displacements is given by the curve 3 of Fig. 3 and the initial displacement $u_{R \text {,in }}$ is given by the following equation, which replaces the Equation 21:

$u_{R, \text { in }}=u_{R, \max } \cdot\left(\frac{1}{3} \cdot e^{-0.15 \cdot \frac{R_{p l}\left(\sigma_{R, q q}\right)}{R}}\right)+\Delta$
The distance $\mathrm{d}$ from the face at which the tunnel wall comes into contact with the shield is given by the following Equation 24:

$$
d=-\frac{2}{3} \cdot R_{p l}\left(\sigma_{R, e q}\right) \cdot \ln \left[1-\frac{\Delta}{u_{R, \max } \cdot\left(1-\frac{1}{3} \cdot e^{-0.15 \cdot \frac{R_{p l}\left(\sigma_{R, e q}\right)}{R}}\right)}\right]
$$

Then, in the presence of an over break $\Delta$ is detected:

- An increase in the value of $u_{R, i n}$; it has the effect of reducing the final load $\sigma_{\mathrm{R}, \mathrm{eq}}$ on the lining (Fig. 1)

- A reduction in the value of $\delta$; it results in a reduction of the pressure applied by the tunnel wall to the shield extrados

If then, due to a high over break, $d$ turns out to be greater than the length $\mathrm{L}$, the tunnel wall doesn't come in contact with the shield and on it is not applied any radial pressure (except the reaction to the own weight); the average thickness of the outer ring of the filling material $t_{\mathrm{g}}$ is no longer simply given by the thickness of the shield in the tail zone $t_{\text {sh }}$, but by the following Equation 25:

$$
t_{g}=t_{s h}+\Delta-u_{R, \max } \cdot\left[\begin{array}{l}
\left(1-\frac{1}{3} \cdot e^{-0.15 \cdot \frac{R_{p l}\left(\sigma_{R, e q}\right)}{R}}\right) \\
\left(1-e^{-\frac{3 \cdot L}{2 \cdot R_{p l}\left(\sigma_{R, e q}\right)}}\right)
\end{array}\right]
$$

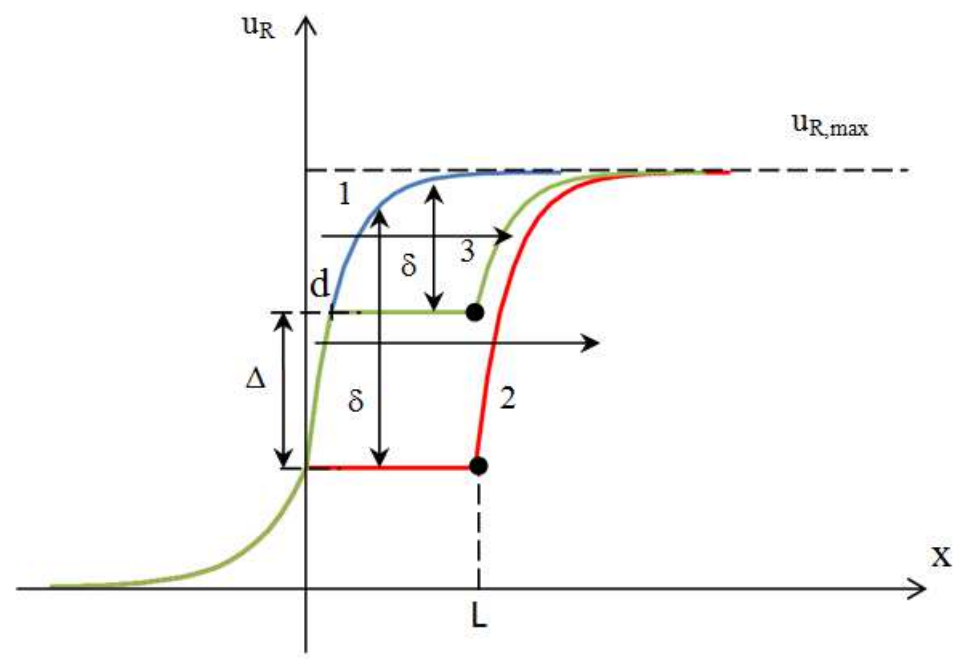

Fig. 3. Longitudinal profile of the radial displacements of the tunnel wall. Key: 1: Curve obtained from the equations of Vlachopoulos and Diederichs (2009) (Equation 19 and 20); 2: Modified curve to account for the presence of a shielded TBM in the absence of over break of the head; 3: Curve modified to take into account the presence of a shielded TBM with over break of the head equal to $\Delta ; \delta$ : Displacement prevented by the shield TBM which has as a consequence that a radial pressure is applied on the outer surface of the shield; L: Length of the TBM shield 


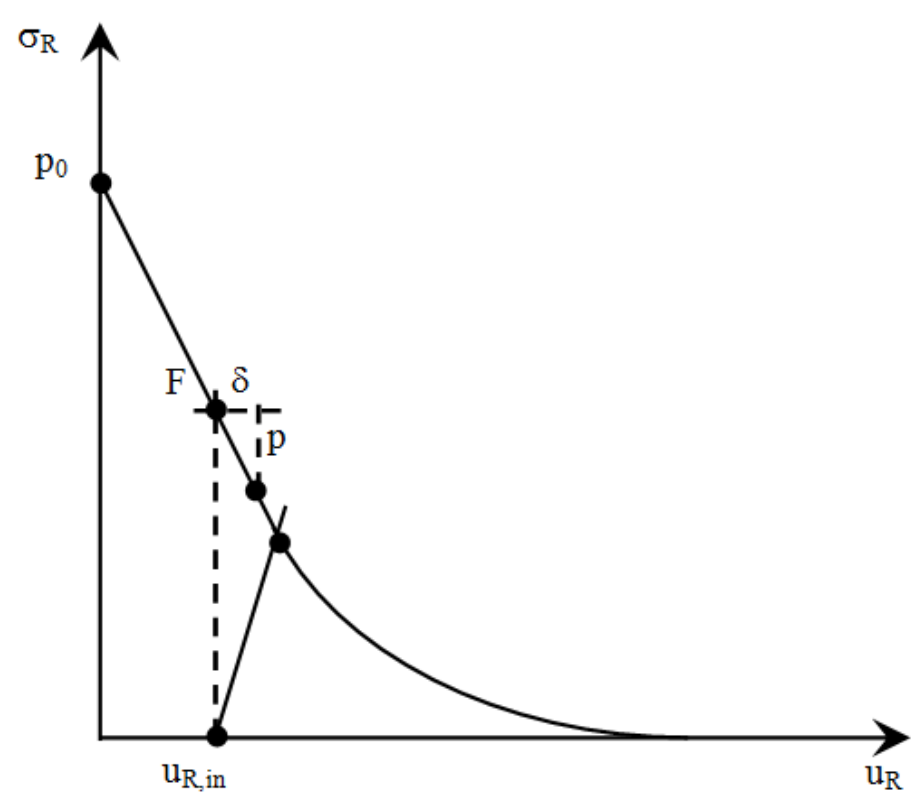

Fig. 4. Evaluation of the pressure $\mathrm{p}$ that the tunnel wall applies to the TBM shield during its advancement, starting from the prevented displacement $\delta$ of Fig. 3. Key: F: Point of the tunnel characteristic curve which has a radial displacement $\mathrm{u}_{\mathrm{R}, \text { in }}$

In this case, $\mathrm{u}_{\mathrm{R}, \text { in }}$ is obtained by the following equation, which replaces the Equation 21 or 23:

$$
\begin{aligned}
& u_{R, \text { in }}=u_{R, \max } \cdot\left(\frac{1}{3} \cdot e^{\left.-0.15 \cdot \frac{R_{p l}\left(\sigma_{R, e q}\right)}{R}\right)}\right. \\
& +\Delta-u_{R, \max } \cdot\left[\left(1-\frac{1}{3} \cdot e^{-0.15 \cdot \frac{R_{p l}\left(\sigma_{R, q q}\right)}{R}}\right) \cdot\left(1-e^{-\frac{3 \cdot L}{2 \cdot R_{p l}\left(\sigma_{R, e q}\right)}}\right)\right]
\end{aligned}
$$

The increase of the average thickness of the outer ring of filling material $\left(\mathrm{t}_{\mathrm{g}}\right)$ involves a reduction of the total stiffness of the support system $\mathrm{k}_{\text {sys }}$ (Equation 18), with additional effects on the reduction of the final load on the concrete lining.

Since both $\mathrm{u}_{\mathrm{R}, \max }$ and $\sigma_{\mathrm{Req}}$ depend on $\mathrm{u}_{\mathrm{R} \text {,in }}$ and also $u_{R, \text { in }}$ (Equation 21, 23 or 26) depends in turn on $u_{R, \max }$ and $\sigma_{\text {Req }}$, it is necessary to proceed iteratively, starting from an initial value of $u_{R \text {,in }}$ equal to 0 , to obtain the convergence of the following three values: $u_{R \max }, \sigma_{R e q}, u_{R, \text { in }}$.

Once obtained $u_{R, \max }$ and $u_{R, \text { in }}$ one can determine the load acting directly on the concrete lining $\left(\sigma_{\mathrm{r}}\right.$ at $\left.\mathrm{r}=\mathrm{R}-\mathrm{t}_{\mathrm{g}}\right)$ in the following way:

- Replacing $\mathrm{u}_{\mathrm{R}, \max }$ to $\mathrm{u}_{\mathrm{R}}$ in Equation 15 and 8, obtaining the $\mathrm{A}_{1}$ and $\mathrm{B}_{1}$ parameters

- The radial stress $\sigma_{\mathrm{r}}$ at $\mathrm{r}=\mathrm{R}-\mathrm{t}_{\mathrm{g}}$ is then given by the following equation (starting from Equation 5, 2 and 3):

$$
\sigma_{r}\left(r=R-t_{g}\right)=C_{1} \cdot\left[A_{1}-\frac{B_{1}}{\left(R-t_{g}\right)^{2}}\right]+D_{1} \cdot\left[A_{1}+\frac{B_{1}}{\left(R-t_{g}\right)^{2}}\right]
$$

\section{Results}

The procedure described in paragraph 2 has been applied to the case of a circular tunnel of radius $3 \mathrm{~m}$, excavated in a rock mass of medium geomechanic quality with the following characteristic parameters: Elastic modulus $\mathrm{E}=8434 \mathrm{MPa}$, Poisson's ratio $v=$ 0.3 , cohesion $\mathrm{c}=0.19 \mathrm{MPa}$, friction angle $\varphi=35^{\circ}$, dilatancy $\Psi=25^{\circ}$. The lithostaticstress $p_{0}$ to the depth of the tunnel is $5 \mathrm{MPa}$. The thickness of the shield in the tail zone $t_{s h}$ is equal to $10 \mathrm{~cm}$. The thickness of the concrete lining $t_{c}$ is equal to $0.3 \mathrm{~m}$. The mechanical characteristics of the used concrete are the following: $\mathrm{E}=28000 \mathrm{MPa}, v=0.15$.

It is assumed the use of natural or injected gravel as a fill of the outer ring of the support system, with an elastic modulus ranging from $100 \mathrm{MPa}$ to $4000 \mathrm{MPa}$ (Poisson's ratio of the filling material was assumed equal to 0.3$)$. It is deemed null the over break $(\Delta=0)$ and, therefore, the tunnel wall comes into contact with the shield immediately behind the excavating head $(d=0)$.

Figure 5 shows the trend of the overall stiffness of the support system $\left(\mathrm{k}_{\text {sys }}\right)$ varying the elastic modulus of the fill material. In Figure 6 is shown the trend of the load acting on the segmental lining $\left(\sigma_{\mathrm{r}}\right.$ at $\left.\mathrm{r}=\mathrm{R}-\mathrm{t}_{\mathrm{g}}\right)$ varying the elastic modulus of the fill material.

The characteristic curve which is obtained from the calculation for an elastic modulus of the filling material equal to $1000 \mathrm{MPa}\left(\mathrm{k}_{\mathrm{sys}}=602.45 \mathrm{MN} / \mathrm{m}_{3}\right)$, is shown in Fig. 7. 


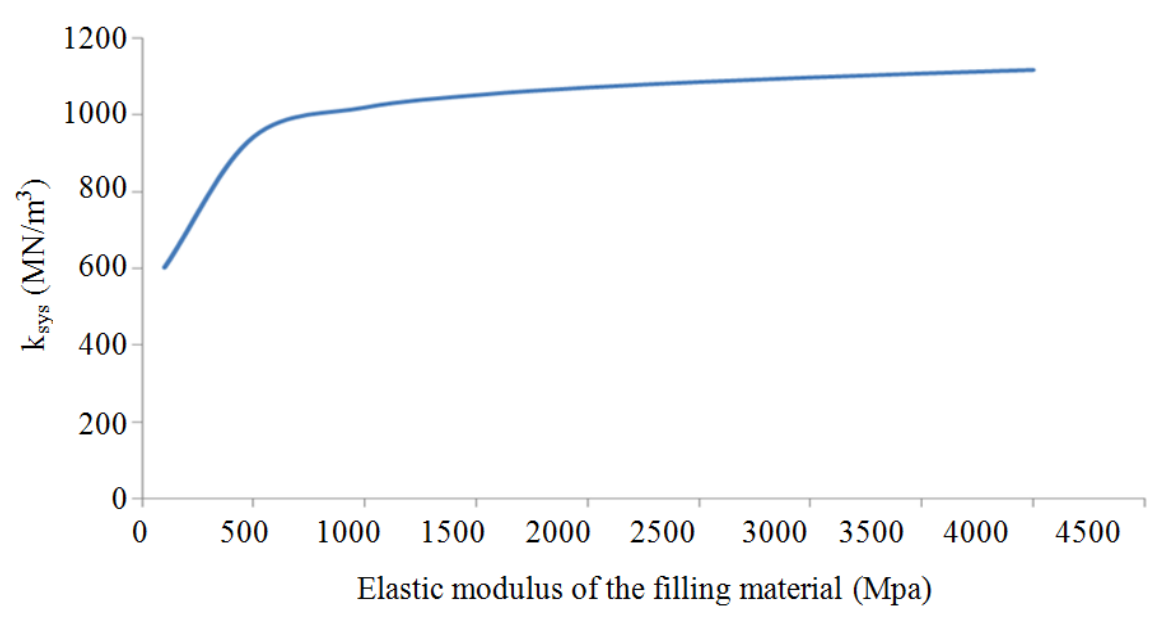

Fig. 5. Trend of the overall stiffness of the support system (ksys) varying the elastic modulus of the material constituting the filling of the outer ring to the segmental lining

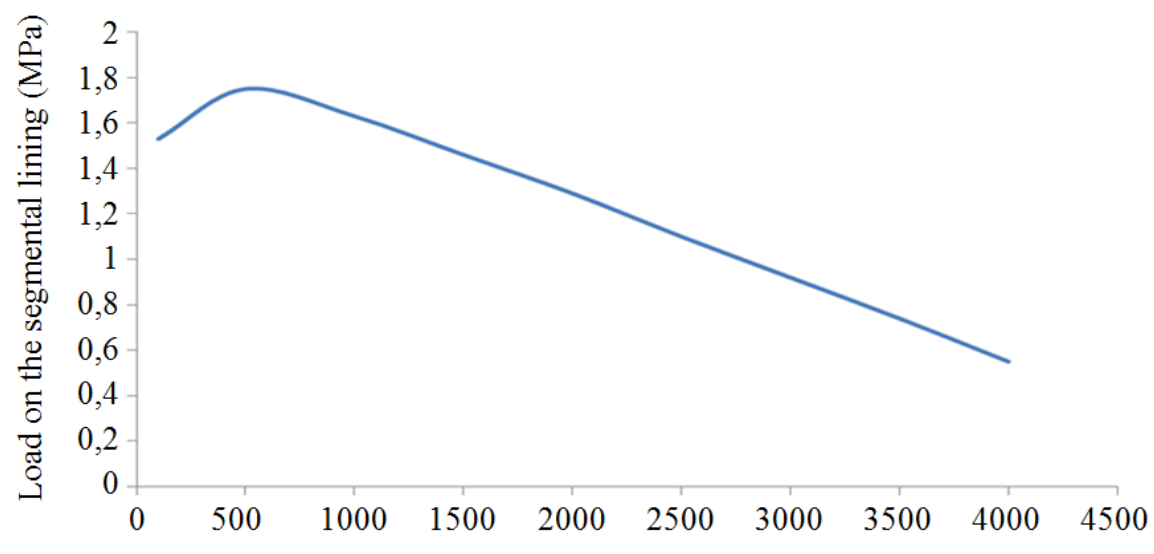

Elastic modulus of the filling material (Mpa)

Fig. 6. Trend of the radial load on the extrados of the segmental lining ( $r=\mathrm{R}-\mathrm{tg}$ ) varying the elastic modulus of the material constituting the filling of the outer ring to the segmental lining

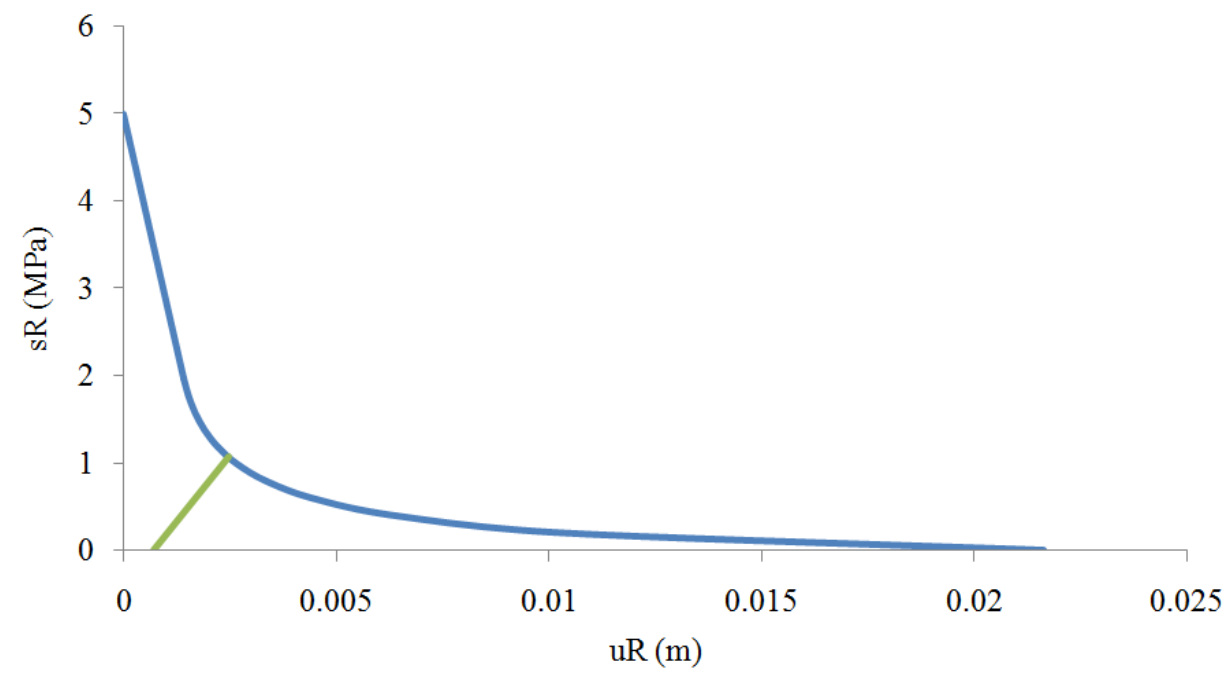

Fig. 7. Tunnel convergence-confinement curve (characteristic curve of the tunnel) and reaction line of the support system, in the studied case and for elastic modulus of the filler material equal to $1000 \mathrm{MPa}\left(\mathrm{k}_{\mathrm{sys}}=602.45 \mathrm{MN} / \mathrm{m}^{3}\right)$ 


\section{Discussion}

From the analysis of Fig. 5 can be detected as the elastic modulus of the material filling the inter space outside the segmental lining has a certain influence on the overall stiffness of the support system, in particular for relatively low elastic moduli. With an increase of the elastic modulus of the filling material, the increase in the overall stiffness of the support system is attenuated, with a tendency to an asymptotic value. The elastic modulus of the fill, presents, instead, a significant influence on the load acting on the segmental lining, even for high values of the elastic modulus (Fig. 6). Increasing the elastic modulus of the fill material, the load on the segmental lining tends to decrease significantly. It can, therefore, be very convenient to be able to intervene on the filling material through the injection of cement mortar, thereby increasing its elastic modulus, in order to contain the loads on the segmental lining. This would result in a reduction of the thickness of the segmental lining, with significant operational and economic advantages and/or of incidence of steel reinforcing, which would be necessary to provide in its interior.

\section{Conclusion}

The support of a tunnel excavated using a shielded TBM machine requires the presence of two different materials: The concrete segmental lining mounted in the tail of the TBM shield and a filling material inserted in the inter space between the segmental lining and the tunnel wall.

In order to effectively analyze the interaction between this support system and the tunnel, a computational procedure that is based on the convergence-confinement method and on the studies of Vlachopoulos and Diederichs (2009) was developed. It was possible, through a detailed analysis of the stresses and strains that develop in the two materials of the composite support system, to obtain the overall stiffness useful to draw the support reaction line of the convergence-confinement method. The study of the evolution of the radial displacements along the longitudinal section of the tunnel, in the presence of a shielded TBM, allowed to obtain the equations able to calculate the $u_{R, \text { in }}$ displacement in the wall at the point where the support system is installed.

The calculation relating to a specific case has allowed to understand the importance of the stiffness of the filling material on the overall stiffness of the system and on the loads which affect the segmental lining.

\section{Acknowledgement}

This research was performed with use of the equipment of the DIATI Department of Politecnico di Torino.

\section{References}

AFTES, 1993. Groupe de travail n.7Soutenementetrevetement, Emploi de la méthode convergence-confinement, Tunnels et ouvragessouterrains, Supplément au n.117, maj-juin.

Benato, A. and P. Oreste, 2015. Prediction of penetration per revolution in TBM tunneling as a function of intact rock and rock mass characteristics. Int. J. Rock Mechanics Min. Sci., 74: 119-127. DOI: 10.1016/j.ijrmms.2014.12.007

Do, N.A., D. Dias, P. Oreste and I. Djeran-Maigre, 2014a. Three-dimensional numerical simulation of a mechanized twin tunnels in soft ground. Tunnell. Underground Space Technol., 42: 40-51. DOI: 10.1016/j.tust.2014.02.001

Do, N.A., D. Dias, P. Oreste and I. Djeran-Maigre, 2014b. Three-dimensional numerical simulation for mechanized tunnelling in soft ground: The influence of the joint pattern. Acta Geotechnica, 9: 673-694. DOI: 10.1007/s11440-013-0279-7

Oreste, P., 2005. A probabilistic design approach for tunnel supports. Comput. Geotechn., 32: 520-534. DOI: 10.1016/j.compgeo.2005.09.003

Oreste, P.P., 2009. Face stabilisation of shallow tunnels using fibreglass dowels. Proc. Institut. Civil Eng. Geotechnical Eng., 162: 95-109. DOI: 10.1680 /geng.2009.162.2.95

Oreste, P., 2013. Face stabilization of deep tunnels using longitudinal fibreglass dowels. Int. J. Rock Mechanics Min. Sci., 58: 127-140. DOI: 10.1016/j.ijrmms.2012.07.011

Osgoui, R.R. and P. Oreste, 2007. Convergence-control approach for rock tunnels reinforced by grouted bolts, using the homogenization concept. Geotechn. Geolog. Eng., 25: 431-440. DOI: $10.1007 / \mathrm{s} 10706-007-9120-0$

Panet, M., 1995. Le Calcul Des Tunnels Par La Méthode Convergence-Confinement. 1st Edn., Presses de l'écolenationale des Pontsetchaussées, Paris, ISBN-10: 2859782303, pp: 178.

Ribacchi, R. and R. Riccioni, 1977. Stato di sforzo e deformazione intorno ad una galleria circolare. Gallerie e Grandi Opere Sotterranee, 5: 7-18.

Vlachopoulos, N. and M.S. Diederichs, 2009. Improved longitudinal displacement profiles for convergence confinement analysis of deep tunnels. Rock Mech. Rock Eng., 42: 131-146. DOI: 10.1007/s00603-009-0176-4 